\title{
Reconstrucción intraétnica: reflexiones acerca de los procesos de reconstrucción territorial en Koliko, en la comuna de Carahue, IX Región
}

\section{Intra-ethnic reconstruction: reflections on the territorial reconstruction processes in Koliko, district of Carahue, IX Region}

Recibido: 24 de enero de 2010 Aprobado: 30 de junio de 2011

Sergio Caniuqueo Huircapan ${ }^{1}$

\begin{abstract}
RESUMEN
El presente documento tiene por objeto hacer una reflexión desde las ciencias sociales para abordar los esfuerzos de reconstrucción intraétnica, a partir de la reconstrucción de territorios mapuche, abordando los problemas de fuentes y de metodología a partir del mapuche kimun y la ciencia, como perspectivas de conocimientos capaces de complementarse.
\end{abstract}

Palabras clave: Reconstrucción territorial mapuche, ciencias sociales, perspectivas de conocimiento.

\section{ABSTRACT}

The object of the present document is to reflect from the perspective of the social sciences on efforts at intra-ethnic reconstruction, starting from the reconstruction of Mapuche territories. Consideration is given to the problems of sources and methodology from the points of view of Mapuche kimun and western science, as perspectives of knowledge which are capable of complementing one another.

Key words: Mapuche territorial reconstruction, social sciences, perspectives of knowledge.

Estudiante Magíster de Estudios Latinoamericanos, Universidad de Chile. Becario Fundación Ford, Comunidad de Historiadores Mapuche. Correo: sergiocaniuqueo@gmail.com 
Introducción

A partir de la década de los 90 se ha posesionado un discurso al interior de la elite dirigencial e intelectual mapuche: el Territorio, el cual a esta altura se ha convertido en un metarrelato, en el sentido que pareciera dar todas las respuestas a la proyección de las naciones originarias. Hasta el momento no existen metodologías claras para abordarlo, así que la mayoría de los esfuerzos se ha ido por una veta descriptiva. A principios de los $90^{2}$, las primeras posiciones se encontraban discutiendo sobre el concepto de pueblo, tierras y desarrollo, esta discusión se entabla a partir de la futura promulgación de la Ley Indígena 19.253, que es promulgada en 1993 y que crea a la CONADI. Llama la atención como José Bengoa, en ese tiempo director de la $\mathrm{CEPI}^{3}$, en un panel denominado Tierras Indígenas, cercena el concepto de territorio que plantea el art. 169 de la OIT y solo se enfoca en hablar de tierras indígenas, como lo plantea este cuerpo legal, en base a las tierras que habitan los indígenas o aquellas que hayan sido reconocidas por el Estado, el resto de la explicación se ha situado en los procesos de reconocimientos de tierras por parte del Estado; llama la atención que en dicho seminario es invitado un experto de la OIT, de la oficina del Perú, Jorge Dandler, quien se enfoca en solo hablar del concepto de pueblo y de participación. Nos encontramos así con la censura del concepto de territorio:

"Es preciso,..., situarse desde un punto de vista necesariamente jurídico para hacer operativo el concepto. Tierra Indígena es un concepto que no solamente se refiere a la tierra que fue ocupada o donde hubo algún grado de ocupación por parte de indígenas... en este sentido, las tierras indígenas chilena fueron "todas las tierras", todo el territorio de lo que hoy es nuestro país, lo que hace al concepto demasiado amplio para ser operacional ${ }^{4}$

A diferencia del Aukiñ Wallmapu Gulam que, en esa misma época, propiciaba la reivindicación del territorio ancestral mapuche, en sus Principios y Planteamientos, "... que parte desde el Biobío al sur, considerando que dentro de este espacio físico nuestro pueblo ejerció plena autodeterminación territorial, política, jurídica e institucional hasta 1881..."

Como apreciamos, este discurso no es solo del Aukiñ Wallmapu Gulam, sino de una gran parte de organizaciones ${ }^{6}$ que no participan del proceso de construcción de la ley indígena. Entre ellas se encuentra el CEDEMLiwen, postura que quedó más clara con su propuesta autonómica, basada también en un reconocimiento del territorio ancestral reconocido por la Corona española en los parlamentos celebrados en los siglos XVII y XVIII, precisando estos últimos los límites territoriales.

"... todo aquello que tiene relación con el derecho territorial mapuche que pese a permanecer olvidado por el Estado chileno, su existencia no es desconocida, porque éste es un derecho que obedece al principio de imprescriptibilidad que solo puede desaparecer con la extinción de un pueblo. Son las materias que competen al derecho territorial, la administración política del área geográfica territorial mapuche, el uso y aprovechamiento de los recursos naturales del suelo y del subsuelo, incluido su área marítima, el desarrollo de infraestructura en materia de obras públicas, el desarrollo de la sociedad mapuche en todos los niveles de conocimiento y las ciencias, arte y cultura..."7.

2 Comisión Chilena de Derechos Humanos, 1992, Pueblo, Tierra, Desarrollo; Conceptos Fundamentales para una nueva ley indígena; Comisión Chilena de Derechos Humanos. Santiago-Chile.

3 Comisión Especial de Pueblos Indígenas. Creada una vez llegado al poder Patricio Aylwin, comisión que era parte del pacto de Nueva Imperial de 1989 y que servirá de base para iniciar una discusión acerca de la implementación de una nueva Ley Indígena y de una institución, una corporación, para el desarrollo de los indígenas.

4 Bengoa, José, 1992, "Las Tierras Indígenas en la legislación chilena", en Comisión Chilena de Derechos Humanos; Pueblo, Tierra, Desarrollo; Conceptos Fundamentales para una nueva ley indígena. Pág. 41.

5 Aukiñ Wallmapu Ngulam, 1997, El Pueblo Mapuche y sus Derechos Fundamentales; AWG; Temuco-Chile. Pág. 89 Anexo de los principios y planteamientos del AWG.

6 Editorial del Boletín Etnológico y Cultura Mapuche de la Sociedad Pelondungun, publicación № 15, julio de 1991. Pág. 3.

7 Actividad desarrollada por el Instituto de Estudios Indígenas de la Universidad de La Frontera en Temuco. 
En 1995 comenzamos a observar los primeros escritos sobre territorios, entre ellos se encuentra el seminario Tierra, Territorio y Desarrollo Indígena, en él aparecen un cambio conceptual y se pasa de la reivindicación del Wallmapu o Walmapuche, como territorio nacional mapuche que involucra Gulu mapu ${ }^{8}$ y Puel mapu', a los territorios reivindicados por identidades territoriales, mencionando que son todavía categorías de análisis, con lo que no necesariamente tendría que existir una coherencia con los conceptos utilizados por la dirigencia. Cabe destacar el concepto de etnoterritorio planteado por Molina:

"Los etno-territorios constituyen una categoría que da cuenta de los espacios habitados por pueblos indígenas o una parte de éstos, que posee por características, encontrarse delimitados por hitos geográficos, reconocidos socialmente por una o más agrupaciones de una misma etnia o de otra distinta. Estos territorios son valorizados por los indígenas, al asignarle un contenido político, económico, social y religioso" 10 .

Sin duda este concepto comienza a acercarse a lo que actualmente son los discursos de los dirigentes indígenas, en cuanto a su concepción de territorios. Pero es Christian Martínez Neira quien comienza a instalar, para el caso chileno, el concepto de Identidad Territorial ${ }^{11}$, como categoría de análisis, para ello describe la identidad lafkenche en cuanto a su localización basado a partir de la cosmovisión desarrollada a esa época, muy influenciada por los escritos de María Ester Grove. Martínez amplia la mirada desde la perspectiva de la etnicidad:

"Aquí hablaremos de territorio para denominar a aquel conjunto de tierras que posen alguna unidad de dominio político por una parcialidad mapuche que se identifique como tal. En otras palabras, es la parcialidad o el conjunto de parcialidades mapuche que logran dominio e identidad colectiva sobre un conjunto territorial. De aquí que el concepto de territorio sea esencialmente político y se exprese en una cierta soberanía y autonomía para ejercer el poder, lograr el dominio de tierra y un sentido de pertenencia particular"12.

Tanto la definición de Martínez como las declaraciones de diversas organizaciones indígenas hablaban ya del territorio en función de ejercer un poder, de ser un contrapeso al Estado. Pero en función de ver el territorio como un espacio a construir, en donde se disputan estilos de vida, en el fondo el establecer elementos que generan un frontera étnica,

"..., el foco de la investigación es el límite étnico que define al grupo y no el contenido cultural que encierra. Por supuesto, los límites a los cuales debemos dedicar nuestra atención son límites sociales, aunque bien puedan contar con su concomitante territorial... Los grupos étnicos no están basados simplemente o necesariamente en la ocupación de territorios exclusivos; necesitamos analizar los diferentes medios por los cuales logran conservarse, pues no es solo mediante un reclutamiento definitivo, sino en virtud de una expresión y una ratificación continuas" 13 .

Ya en 1996 la Corporación Nacional de Desarrollo Indígena (CONADI) crea una colección: La Propiedad Indígena en Chile. En ella participan investigadores como Raúl Molina, Martín Correa, Rolf Foerster, Jorge Vergara, José Aylwin, por nombrar algunos. Llama inte-

Sector perteneciente a los que es actualmente Chile entre el Biobío y Chiloé.

9 Sector correspondiente a lo que es actualmente Argentina y que involucra las Pampas y Patagonia.

10 Molina, Raúl, 1995, "Reconstrucción de los Etnoterritorios", en: Tierra, Territorio y Desarrollo Indígena; Institutos de Estudios Indígenas UFRO; Temuco-Chile.

11 Hay un primer trabajo de este autor, que trabaja el tema de la identidad; ¿Identidades étnicas en el mundo mapuche contemporáneo? Algunas implicancias teórico prácticas; en Rev. Pentukun $\mathrm{N}^{\circ} 2$; Instituto de Estudios Indígenas de la Universidad de La Frontera.

12 Martínez, Christian, 1995, Comunidades y Territorios Lafkenche, los mapuche de Rucacura al Moncul; Instituto de Estudios Indígenas de la Universidad de La Frontera, Temuco. Pág. 13.

13 Barth, Fredrik (comp.) 1976. Los grupos étnicos y sus fronteras. La organización social de las diferencias culturales. Fondo de Cultura Económica. México. Pág. 17. 
resantemente la posición frente a la noción de territorio del Director Nacional de la CONADI de ese tiempo, Mauricio Huechulaf Cayuqueo, quien más tarde es removido de su cargo por no autorizar las permutas ligadas al caso Ralko.

... la situación actual puede caracterizarse en términos territoriales como un período de gran importancia, debido a que se encuentra en juego la integridad territorial de las comunidades, que se ven amenazadas por proyectos de desarrollo que no tienen relación directa con el etno-desarrollo ${ }^{14}$.

Cabe mencionar que la colección antes mencionada toma el concepto de territorio en torno a la localización desde la perspectiva mapuche y a describir hábitat y formas de vida, pero deja de lado la reivindicación territorial centrándose exclusivamente en la propiedad dejada por el título de merced, reconocimiento del Estado que se desarrolló en el período entre 1881 a 1929 y de la cual quedaron excluido los Williche de las actuales provincias de Llanquihue y Chiloé. Cabe mencionar que la Colección abordó a todos los pueblos indígenas, pero para el caso mapuche quedó incompleta la Araucanía, en la cual no se publicó la provincia de Malleco y no se realizó la investigación para el caso de Cautín, pareciera ser peligroso abordar el tema de la propiedad. ¿Qué más sería abordar el tema del territorio basado en el derecho internacional?

Con una visión distinta se escribe hacia 1997 Ralco. Modernidad o etnocidio en territorio Mapuche, compilación a cargo del antropólogo Roberto Morales. En la cual el concepto territorio es la del territorio vivido, centrado en todos los planos culturales, no es la simple la propiedad, se enfoca en el derecho de oponerse legítimamente a un megaproyecto como es una central hidroeléctrica. Existe una orientación al ver a un actor social planteando sus propuestas y su lucha, a partir de la relación del territorio en un pasado, en el presente y en un futuro. Basada en una visión parecida estaría Marcos Gutiérrez, en cuanto a las sociedades y la construcción territorial:

"... importa reflexionar,..., como se comportan los individuos y las sociedades en relación al proceso de construcción de un sistema territorial, en un espacio geográfico que tiene una organización y un ordenamiento funcional a los individuos y a las sociedades que la ha concebido. En otras palabras, la sociedad mapuche organiza y organizaba su espacio y concebía su territorio en su función con que contaba para ello, y los requerimientos que su grado de organización socio-cultural le demandaba ${ }^{15}$.

Como se aprecia, la territorialidad implica un acto de soberanía y, por ende, política, pero al mismo tiempo nos lleva a la visión desde la perspectiva social al generarse una opción de vida. Visión que desarrolló el Proyecto Mapu-Territorialidad, la cual aborda los aspectos presente en los procesos de construcción de estas realidades ${ }^{16}$. En estos escritos vemos la interrelación de los diversos actores, principalmente a partir de los siglos XIX y XX se aprecia la actual conformación de este territorio y el surgimiento de lo que nosotros denominamos antagonismos territoriales a partir de una formación social y económica, y por ende espacial:

"Tenemos que tener presente que los agentes son componentes de una sociedad específica, como lo es una formación

14 Molina, Raúl \& Correa, Martín, 1996, Territorio y Comunidades del Alto Biobío; CONADI; Chile. Pág. 8.

15 Gutiérrez, Marcos, 1998, "La territorialidad en el proceso de ocupación de La Araucanía: un enfoque Geográfico- Histórico"; en Rev. Pentukun N 9; Instituto Estudios Indígenas de la Universidad de La Frontera, Temuco. Pág. 63.

16 Se pueden analizar las siguientes publicaciones:

Aylwin, José (comp.), 2001, Políticas Públicas y Pueblo Mapuche, Instituto Estudios Indígenas de la Universidad de La Frontera, Ediciones Escaparate, Temuco.

McFall, Sara (comp.), 2001, Territorio Mapuche y Expansión Forestal, Instituto Estudios Indígenas de la Universidad de La Frontera, Ediciones Escaparate, Temuco.

Morales, Roberto (comp.), 2001, Municipios: Participación (o exclusión) mapuche, Instituto Estudios Indígenas de la Universidad de La Frontera, Ediciones Escaparate, Temuco.

Mariman, Pablo (comp.), 2002, Parlamento y Territorio Mapuche, Instituto Estudios Indígenas de la Universidad de La Frontera, Ediciones Escaparate, Temuco.

Morales, Roberto (comp.), 2002, Territorialidad Mapuche en el siglo XX, Instituto Estudios Indígenas de la Universidad de La Frontera, Ediciones Escaparate, Temuco. 
social y económica, y sus instituciones buscan plasmar en el territorio su visión de mundo para dar forma a su sociedad y que se mantenga como unidad étnica en el tiempo. Temuco puede ser catalogada como una Sociedad Fronteriza, articulada marginalmente a la economía y sociedad nacional, al igual que su proceso de globalización. Es una sociedad en la que se emiten discursos políticos e ideológicos con los cuales se plantea cuál debe ser el uso correcto del territorio, o sea, la cosmovisión fronteriza, en parte formada por la herencia cultural occidental $y$, por otro lado, por su carácter de frontera étnica, ante la cual la presencia y relación con el "otro" es explicada con categorías como: mapuche = mal uso de la tierra, mapuche = flojo, mapuche = falto de educación . Como podemos ver, la diferencia es expresada incluso en un maniqueísmo en lo cual chileno $=$ civilizado, chileno $=$ buen uso del territorio, etc. ${ }^{17}$.

Es así como del concepto de territorio se comienza a evolucionar a la configuración del espacio, no es la reivindicación del espacio, sino la construcción de él lo que se encuentra en juego. Es así como el concepto de territorio es significativo para algunas comunidades mapuche hacia el 2005:

"... el concepto de Territorio se constituye sobre la base de los elementos materiales $e$ inmateriales. Los elementos materiales son las tierras donde habitan los pueblos indígenas y los recursos que hay en ellas. Los elementos inmateriales son el patrimonio cultural e intelectual, las leyes, las costumbres, sistemas de tenencia, forma de organización e instituciones. En síntesis, territorio indígena involucra que las comunidades poseen las tierras y los recursos naturales del espacio en donde habitan e influyen y se desarrollan autogestión política, económica, social y cultural de dicho espacio ${ }^{18}$.
De esta manera, queremos ver este análisis, en cómo se construye el territorio mapuche a partir de sus propios actores. Basado en lo material e inmaterial, en lo histórico, presente y futuro, en el proceso a generar autogestión evaluando desde sus perspectiva lo que han construido y su visión de futuro.

Análisis histórico de la construcción del territorio, desde la perspectiva étnica

La historia mapuche, inserta en un proceso de reconstrucción territorial, puede ser desarrollada desde dos perspectivas dominantes de conocimiento, la ciencia occidental y el Kimun Mapuche. Esto se produce por distintos motivos, sea por los niveles y objetivos que se propone el investigador y/o los "sujetosobjetos", sea por la acción dialéctica en la metodología, puesto que involucra una construcción social, e incluso por los contextos en que es producida la historia como discurso ideológico. Esta historia debe sobrepasar dos riegos clave, como son la relación de dominación entre winka y mapuche, estableciendo una frontera étnica y la autorreferenciación sin la crítica interna.

A continuación desarrollaremos una explicación acerca del uso y el sentido de la Historia en un proceso de reconstrucción territorial, a través de la descripción y el análisis crítico, y la utilización de ciertas fuentes y no de otras

Para la utilización de las fuentes, el historiador convencional se encasillaría fundamentalmente a las fuentes documentales, esto quiere decir, a documentos escritos; para ello se debe identificar dónde se encuentran dichos documentos. Para nuestro caso, las fuentes se localizan en el Archivo Regional de la Araucanía (ARA), esencialmente en los Fondos Intendencia de Cautín, Gobernación de Imperial, Memorias Ministeriales, Boletines de Leyes y Decretos, Juzgados Criminales y Civiles de Nueva Imperial y el Conservador de Nueva Imperial, puesto que en él se encuentra

17 Caniuqueo, Sergio, 2005, Wiñon Mapuche Kisügunehual. De la reconstrucción territorial a la soberanía mapuche, Tesis para optar al grado de Licenciado en Educación, Universidad de La Frontera, Temuco. Pág. 29.

18 Figueroa, Noelia (responsable de la edición), 2005, Aprendizaje para la autogestión territorial Mapuche, Experiencias de cinco organizaciones territoriales indígenas, Inédito. Pág. 19. 
la primera disposición de ordenamiento territorial ocurrido con las comunidades indígenas, el Fisco y los particulares.

Al revisar los fondos, fuimos encontrando que el trabajo con fuentes documentales del siglo XX obliga a diseñar una nueva metodología de construcción de la historia. Esta consiste en unir fragmentos para construir cuadros coherentes, principalmente de la acción estatal, diluyendo la historia mapuche propiamente tal. La producción estatal se orienta en recopilar datos exclusivamente para sus intereses y objetivos a cumplir, por lo cual, no permite conocer una historia acabada de los territorios. Por ejemplo, las Memorias Ministeriales se orientan a informar al ministerio pertinente, el cual, a su vez, desarrolla un informe final para informar al Congreso. Estos informes tienen una visión temporal, anual en la mayoría de los casos, y sintetizan el trabajo administrativo realizado en sus materias pertinentes. Esto tiene que ver con los tipos documentales ${ }^{19}$ que necesita la administración estatal y los formatos que estos poseen. Una memoria ministerial es redactada para ser enviada al Congreso, teniendo un carácter de cuenta pública y sustentada por una medida legal. Por otro lado, la Memoria emitida por un comandante de la frontera tiene un carácter técnico acerca de los avances y tareas que debe ejercer de acuerdo a lo propuesto por su ministerio ${ }^{20}$. Los informes, de anexado como documentos, son materias más específicas y tienen que ver con el cumplimiento de una acción, la cual, a su vez, puede estar relacionada con un objetivo estratégico planificado por el ministerio o por el encargado de ejecutar la acción. Por ejemplo, en la Memoria del Ministerio de Guerra y Marina de 1867 se encuentra la Memoria entregada al Congreso y en ella hay un apartado que se denomina Ocupación de la costa de la Araucanía, ubicándose, en los anexos de dicha memoria, la Memoria del Comandante de la Alta Frontera, Cornelio Saavedra, titulada Memoria de los Trabajos Emprendidos en la Ocupación Militar de la
Costa de la Araucanía en el Año de 1867, al interior de la documentación que acompaña a la Memoria hayándose el Informe Reconocimiento del río i barra del Toltén. Informe y estudio de las desembocaduras de la Cuenca del Toltén y Queule remitido por el Teniente $1^{\circ}$ Francisco Vidal de Gormaz. Fuera de ello se encuentran las órdenes escritas. Podríamos agregar que las estructuras de estas Memorias se caracterizan por entregar una serie de documentos a manera de anexos para establecer las responsabilidades políticas y técnicas, así como la competencia de cada agente dentro de una estructura jerárquica como la que posee el Estado.

Para el caso de los Fondos de la administración local encontramos la Intendencia de Cautín y la Gobernación de Imperial. Ambos nos entregan valioso material para trabajar la relación Estado y Pueblo Mapuche. Para el caso de la Intendencia de Cautín, encontramos información, en términos temporales, de 1895 a 1975, añadiendo que es una información basada en la antigua división política administrativa que tenía el Estado antes de la creación de las regiones en 1980 y que correspondían a provincias. Este Fondo contiene tipos documentales que van desde las Memorias de Intendencia, Gobernaciones y Municipalidades, decretos ministeriales, de Intendencia y Gobernaciones, informes, oficios, resoluciones y cartas; por un tema de tiempo no explicaremos en qué consisten todos los tipos documentales, sino los que tienen mayor relación con la construcción de Historia de los territorios mapuche.

Las materias tratadas son diversas, pero las podríamos clasificar en dos grandes líneas: flujo de las estructuras estatales y relación con la sociedad civil chilena. De la documentación que nos podría interesar y que revisamos se encuentra la producida por el Protector de Indígenas entre 1900 a 1928. Los oficios enviados por el Protector van dirigidos al Intendente para que establezca procedimientos a seguir,

19 Los tipos documentales revelan la jerarquía institucional, así como evidencian la relevancia y contenido de un documento. Los tipos documentales son convenciones establecidas dentro de las prácticas institucionales y muchas veces sustentadas en normativas legales. Poseen en muchos casos un valor de carácter público.

20 Aquí el tipo documental es la memoria, la cual tiene un formato para ser escrito. Lo que diferencia una y otra es el carácter político y público de la primera, en términos de su fin u objetivo a cumplir como producto, mientras que la memoria desarrollada por un subalterno en la jerarquía estatal, cumpliendo con el mismo formato, se opone por el carácter técnico y orientado a una administración interna. 
apoyaban el desempeño para cumplir con sus funciones, muchas de ellas relacionadas con procedimientos policiales y otras con investigaciones acerca de sucesos denunciados por indígenas, particulares o funcionarios públicos. Llama poderosamente la atención la función del Intendente, no en su proceder como sujeto, sino como agente del Estado circunscrito a un poder como el Ejecutivo, delimitado a ejercer ciertas funciones de carácter administrativo, al contrastarlo con una función que raya en el carácter judicial, estableciendo "sentencias" a favor o en contra, o si procedía traspasar a algún juzgado. Por ejemplo, nos encontramos con el reclamo del señor Luis Ubeda ${ }^{21}$, ex militar, que recibió una hijuela por el Ministerio de Tierra y Colonización, en el cual hay un expediente, no completo de este caso, de disputa entre el militar y el longko Lorenzo Paillao ${ }^{22 .}$ La causa muestra gráficamente el accionar estatal, de los privados y de los indígenas, lamentablemente la causa no se encuentra completa y por lo tanto desconocemos el desenlace de esta disputa. Por los datos entregados en ella se sabe que los terrenos en disputa se ubicarían frente a la ciudad de Carahue, cruzando la ribera sur, lo que hoy sería Koyawe, que es uno de los territorios que actualmente estamos estudiando. Sin duda, aparece como una pista atractiva para historiar; se puede corroborar con la gente del territorio los datos; se puede seguir la causa investigado en el Juzgado de Nueva Imperial una causa de agresión propinada a la comunidad de Lorenzo Paillao y Pedro Vergara por parte de la Policía enviada por orden de la Intendencia; sin duda, un hecho de estas características es probable que haya salido en la prensa de la época; podríamos revisar los conservadores y los títulos de merced para corroborar la legítima propiedad; etc.

Pero volviendo a nuestro contexto, no podemos decir que a la gente del territorio no le interesaría, de hecho sí le interesa, pero obliga iniciar una investigación ante la cual no están en condiciones de asumir por los tiempos y recursos que deberían seguir; y para el caso de nosotros, que apoyamos este proceso de reconstrucción, tampoco contamos ni con los tiempos ni son los recursos para desarrollarlos. Para ser más gráficos analizaremos los pasos necesarios con las respectivas dificultades.

Primero que nada, los Fondos documentales del ARA no poseen la suficiente descripción archivística para encontrar datos tan particulares. Por ejemplo, la Intendencia de Cautín tiene más de 620 volúmenes y la Gobernación de Imperial por lo menos unos 100 volúmenes, sin embargo, en los catálogos no aparece el productor de los oficios o informes, como ser el Protectorado de Indígenas, solo queda registrado como oficio recibido o despachado; es por ello que un trabajo de estas características implica revisar cada uno de los volúmenes. Otro inconveniente es la forma en que el Estado organiza sus informaciones y documentos. En la mayoría de los casos, podríamos decir que faltan criterios de organización en la información, se carece de la lógica de organización documental, como son los expedientes, que es el orden en el cual se dio el proceso, con todas sus etapas, desde su inicio hasta su resolución; solamente los juzgados trabajan con esta lógica. Cabe señalar que este desorden administrativo de la información y la falta de una centralidad que permita ordenar y clasificar correctamente a los expedientes y tipos documentales, hacen que la información se encuentre dispersa, muchas veces repetida, pero sin ser ubicada, haciendo que dificulten aspectos administrativos, como la toma de decisiones o que estas se tomen sobre una información parcial e incompleta.

En segundo lugar encontramos el estado de conservación de los documentos, lo cual dificultaría el trabajo investigativo para las personas de territorio que quisieran dedicarse a este tema. Mucha de la documentación ha sufrido deterioro, no por la destrucción del soporte papel, sino por la disolución de tintas a través del tiempo; los más afectados son los papeles que se encuentran entre 1900 a 1930.

21 Fondo Intendencia de Cautín, volumen 11, f 1-31 y 154-159. ARA. Cabe señalar que los productores documentales no son solamente instituciones del Estado, como informes y oficios, también se encuentran los particulares y otras instituciones, como Conservadores y Notarios.

22 Esta causa ha sido trabajada por Florencia Mallon, en la cual logra mostrar la articulación poder central, poder local, uso de la fuerza y finalmente el resultado de Lorenzo Paillao y su familia, quienes son radicados en 1907 bajo el nombre, en el título de merced, de Paillao Curtivil, en el sector de Güedaquintuhue, en Carahue. Ver Mallon, Florencia, 2004, La sangre y el copihue. La comunidad mapuche de Nicolás Ailío y el Estado chileno 1906-2001, LOM Ediciones; Chile. Págs. 40-43. 
Si quisiéramos trabajar los Juzgados, solo los de Temuco están descritos (un fondo judicial puede tener más de 30.000 causas). El Juzgado de Imperial, en el cual se encuentran juicios de la Gobernación, que involucraba Puerto Saavedra, Carahue, Nueva Imperial, Cholchol, entre otras comunas, no están descritos, solo hay un catálogo que indica la cantidad de causas por años, por lo cual el trabajo se dificulta. Para el caso de consultas de periódicos entre 1884 y 1910 , aproximadamente, no existen reproducciones accesibles en regiones, por lo que habría que hacer un trabajo en el Archivo Nacional.

Por los tipos de Fondos y tipos documentales que maneja el ARA, podemos concluir que posee la característica de ser un archivo intermedio e histórico. Es intermedio si tomamos como criterio la vida útil de los documentos que todavía poseen valor para la administración pública y a las personas en general para ser ocupados en procedimientos administrativos. En el mismo sentido se agrega la característica de archivo central, al cual se traspasa la información de los archivos de gestión, que es donde los documentos transitan con su vida útil en forma más activa. Por otro lado, es histórico en el sentido que mucho de estos documentos han pasado su vida útil y son conservados para responder al quehacer de la investigación propiamente tal. Por último la característica de Regional del Archivo responde al cúmulo de documentos que son propios del quehacer administrativo de la región. Como apuntábamos en párrafos anteriores, el ARA es el archivo de la gestión estatal en la región y con ello nos dice que podemos establecer la relación pueblo mapuche y Estado, y solo de manera indirecta nos ayuda a realzar hechos históricos documentados que tienen una interpretación en los territorios, pero no necesariamente logran ser concordante o van a llevar a una historia completa de los territorios mapuche o de las comunidades o del propio pueblo mapuche.

Otro archivo, con características similares al ARA, es el Archivo de Asuntos Indígenas. En él se conservan tres Fondos destacables, los Títulos de Merced, los Juzgados de Indios y las Carpetas Administrativas DASIN. Los Tí- tulos de Merced han perdido su valor jurídico en cuanto a asignación de propiedad a partir del Decreto-Ley $\mathrm{N}^{\circ} 2.568$, dictado por la Junta Militar en 1979, que suprime y modifica la Ley $\mathrm{N}^{\circ}$ 17.729, dictada en 1972 por el Gobierno de Salvador Allende ${ }^{23}$. Hoy poseen un valor administrativo dentro de la actual Ley 19.253, dictada por Patricio Aylwin. Sin duda, se torna un documento relevante para los juicios de restitución de tierra y postulación al subsidio de tierras y agua, a ello se suma la calidad de indígena y la beca indígena. Los Títulos de Merced poseen un catálogo que permite una búsqueda rápida y segura. Por otro lado tenemos los Juzgados, los cuales poseen un índice para la ubicación de alguna causa, básicamente con el nombre del demandante y demandado: existen algunas causas identificadas por el nombre de la comunidad y, en algunos casos, está ubicada la materia del litigio. Para establecer un dato, solamente el Juzgado de Imperial posee $\mathbf{1 8 0}$ unidades de conservación, cada una de ellas con un número superior a las 30 causas, con materias variables de juicios, que van desde la restitución de tierras o de goces, partición, celebración de contratos de arriendos o de compra, tuición, manutención, etc. Hay que recordar que los Juzgados indígenas fueron afectados por dos leyes, la 4.802, que crea los Juzgados de Indios, siendo el decreto 4.111 que los rige de 1931 a 1961, y la 14.511, que fija los Juzgados de Letra de indios. Entre el primer período, que involucra 1928 y 1961, hay una preocupación por litigar básicamente en torno a la tierra. Para esto, el procedimiento era la partición de la comunidad, sin embargo, y pese a los conflictos, fue una pequeña parte de las comunidades que se subdividieron. Con Jorge Alessandri como presidente, se abre una nueva etapa en la legislación indígena que es desarrollada, más tarde, por el gobierno de la Democracia Cristiana de Eduardo Frei, en 1964, al hacer que el Estado comience a intervenir cada vez más en la vida de las familias indígenas y a establecer proyectos de desarrollo, en la cual la legislación indígena crea nuevos instrumentos y combinaciones en los mecanismos administrativos, como era la Dirección de Asuntos Indígenas (DASIN), creada en 1953 (Silva Echeverría, 1966, 215), en la presidencia de Carlos Ibáñez del Campo, con Venancio Coñoepan como Mi- 
nistro de Tierras y Colonización. Producto del Decreto-Ley $\mathrm{N}^{\circ} 2.568$ se anulan los Juzgados de Indios, pasando solo las causas de tierra a la Oficina del DASIN en el INDAP. Las demás causas pasaron a los Juzgados Civiles. Es por ello que este Fondo posee documentación de 1928 a 1978 aproximadamente. La valoración que posee este Fondo es que permite seguir la pista en la evolución del Estado para resolver el conflicto indígena, donde sin duda el trabajo territorial se hace más fácil, pero como anteriormente mencionábamos carece de un catálogo que describa en forma eficiente los contenidos de las causas.

Las carpetas administrativas son las creadas por el DASIN básicamente en la década del 60 para atender aspectos de la legislación indígena que tenían relación con asuntos más administrativos del quehacer comunitario, como expropiaciones para la construcción de escuelas, censos indígenas, etc. En términos temporales estamos hablando entre 1962 a 1978. Junto a esto se encuentran algunos tipos de contratos de arriendos, venta o prohibiciones o interdicciones de goces, figuras legales que se siguen desarrollando después de 1978. A partir del Decreto-Ley $N^{\circ} 2.568$, las carpetas DASIN tienen un cambio en los tipos documentales que manejaban. Aparecen litigios interterritoriales con particulares chilenos, procedimientos de subdivisión de las comunidades, también se encuentran copias de las inscripciones en los conservadores y otros documentos referidos al proceso, como la compensación recibida por el Estado, la entrega de materiales, etc. Comienzan a surgir los conflictos intraterritoriales al interior de las comunidades, en una primera instancia, para impedir la partición; en un segundo momento, después de la división, comienzan los conflictos por materias de alteración de deslindes, servidumbres de tránsitos, adjudicación de hijuelas, etc. A ello se agrega, con la acción del SERVIU, la prohibición de enajenar (vender) para la postulación de vivienda. Ante los reclamos, el DASIN genera expedientes, compuestos por los siguientes tipos documentales: cartas de particulares, informes legales, topográficos, de observaciones en terreno, actas en terreno, oficios y memorandos, etc., los cuales son reunidos y le dan forma al expediente, para más tarde ser sancionados por el director de INDAP Regional. En algunos casos, pese a la información reunida, no se pueden tomar decisiones debido a complejidades del caso, para ello el director derivaba las causas a Juzgados Civiles para que resuelvan. También hay situaciones insostenibles, en las cuales los conflictos interprediales llevaron a la agresión, sobre todo por la subdivisión y los deslindes de los predios.

Analizando los contenidos de los Fondos uno ve con tristeza, como mapuche, el quebrantamiento de nuestras familias; donde parientes utilizan todos los medios para obtener un poco más de tierra o corregir injusticias entre los propios mapuche, donde los sentimientos generados son diversos: desconfianza, envidia, odios, etc. Sin duda, estas heridas han impedido el surgimiento de una organización que pueda acoger a todas las familias mapuche del territorio. Es distinto describir las rencillas a vivirlas diariamente con los vecinos y las familias. Creo que no es posible trabajar estas fuentes sin un procedimiento adecuado y una madurez de los territorios para asumir esta historia. Es fácil escribir en contra del otro, generar una imagen donde el otro sea responsable de mis penurias. Pero qué difícil se hace construir una historia para asumir los dolores, para perdonar y seguir adelante, para entender que fuimos parte de un proceso mayor. Para trabajar estas fuentes hay que despersonalizar al individuo, convertirlo en un cuadro estadístico y evitar que las personas se sientan representadas; es crear una amnesia. Es fácil trabajar los Juzgados de Indios cuando queremos ver la cara del usurpador, su accionar en el tiempo y los métodos utilizados para eludir la justicia, simplemente porque nosotros nos transformamos en verdugos. Con ello no quiero decir que hay que abandonar las causas de usurpación, solo quiero equiparar una actitud: aquella que dice cómo hacernos responsable de nuestra historia y superarla, de cerrar el ciclo, como una vez lo mencionó Bonfil Batalla, para transformarnos en Historia; para abrir nuevos ciclos.

Ahora bien, si analizamos estos contenidos ofrecidos por las fuentes documentales, con las aspiraciones de Historia que urge a las personas de los territorios, no parece haber una concordancia entre ellos, primero que nada, no podemos afirmar que este tipo de documentos sean indiferentes a las personas del 
territorio, ni tampoco que no sean necesarios, por el contrario, se ve como una urgencia. La diferencia entre lo ofrecido por los documentos no responde a aspiraciones acerca de la cosmovisión ni tampoco a un pasado reciente en el cual se busquen los puntos de unión. Los territorios en este proceso necesitan una historia coherente que le explique el pasado inmediato y los una; en el fondo, un nuevo referente ideológico, un nuevo proyecto de sociedad, nuevas orgánicas que permitan una nueva estructura representativa ante el Estado y le den coherencia interna, un marco de movilización social que permita la rearticulación y "reclutamiento social", utilizando el concepto de Stuchik. Lo peligroso de esta idea es caer en un racismo, en una visión fundamentalista que vaya creando una ideología de la exclusión, así como ocurrió con nuestro pueblo. Como mencionaba anteriormente, es fácil construir una historia donde no seamos responsables de nuestros infortunios, en plantear conceptos como la deuda histórica que el Estado tiene con nosotros. Sin duda, hay que analizar esta construcción histórica como parte de un proceso de liberación nacional. Para ello uno de los primeros pasos es la descolonización ideología. Aquí es donde la gente mapuche se orienta en dos conceptos fundamentales para hablar el tema de la historia o el kuifi, como sistema temporal. El primero, relacionado con el pasado lejano y que tiene las siguientes denominaciones, Rüf kuifi em, Fütra kuifi o Wera fütra kuifi ${ }^{24}$. En ella se manejan los conocimientos filosóficos o cosmovisionales, en el fondo son los sistemas ontológicos, epistemológicos y éticos que le dan forma a la sociedad mapuche a partir de un constructo teórico y social. El segundo concepto está orientado con la memoria colectiva y que se denomina we kuifi o ella kuifi, que básicamente está orientado en lo que pasa en el Wayontu mapu (ibíd.) Para nuestro caso analizaremos la Historia de los territorios vistos desde el segundo concepto: para este fin la gente ha establecido cinco categorías: lugar de origen, asentamiento del lugar, lugares comunes y espacios públicos, apellidos y mención de sus fuentes.

\section{Reconstrucción territorial en Koliko ${ }^{25}$}

\section{Análisis geográfico}

El territorio de Koliko se encuentra, según la categoría utilizada por el Instituto Geográfico Militar, en la unidad natural denominada cordillera de la Costa; en la subunidad conocida como Interfluvio Imperial-Toltén ${ }^{26}$. Se caracterizan por la irrupción que genera la acción fluvial, como modeladora, frente a la cordillera de la Costa. Esta acción no es menor, ya que visto desde una perspectiva orográfica tenemos como acción determinante en la cultura la presencia del río Imperial, el cual se establece como ruta de comunicación entre las comunidades costeras y el interior, más conocido como Depresión Intermedia o Valle Central. Bajo esta misma visión, el territorio es parte de las estribaciones de un sistema que se encuentra en esta cordillera de la Costa cercenada, que es las estribaciones de la cordillera de Nahuelbuta; de ahí que el territorios se caracterice por la cantidad de cerros, o en términos geográficos, "ocupado por colinas bajas de formas redondeadas, ampulosas, pero de perfil algo cóncavo; la carta topográfica las presenta con altitudes de 200 $m$ "27 compuesta y moldeados por sedimento fluvial, encontrándose quebradas y cerros con arista, fuera de una gran vegetación.

24 Ancalaf, Gladis; Huenchulaf, Ernesto \& Cárdenas, Prosperito, 2004, Nociones de Tiempo y Espacio en la Cultura Mapuche. Guía didáctica para el profesor. Nivel Básico I, Centro de Desarrollo sociocultural Mapuche, Corporación Nacional de Desarrollo Indígena. Temuco-Chile. Pág. 24.

25 Los datos trabajados se desarrollaron en el marco del trabajo de Investigación Acción participativa en las reuniones talleres de COPAG, que era la formación de un grupo de apoyo a la gestión territorial previas a los talleres de microplanificación territorial; cada territorio poseía su grupo de gestión nominados por los mismos territorios. Otros datos utilizados se encuentran dentro de la investigación sociocultural desarrollada por Ernesto Huenchulaf en el marco de la construcción de Planes Territoriales de Desarrollo para los territorios de Koliko y Koyawe, financiado por el Programa ORIGENES. Huenchulaf es Elche de Ragiñtulewfu (el concepto se refiere a las personas que cultivan el Rakizuam y Kimun mapuche), Director del Centro de Desarrollo Sociocultural Mapuche, dirigente y activista en distintas organizaciones mapuche desde la década del 80 a la actualidad.

26 IGM, 1985, Atlas de la IX Región de La Araucanía, Instituto Geográfico Militar, Chile. Pág. 51. 
La modelación que deja la acción hídrica hace que el agua se ubique en las partes bajas del territorio a través de múltiples esteros que cortan los cerros y lomas existentes. Esta se convierte en una de las formas de acceso al agua; otro acceso son las napas freáticas (aguas del subsuelo) distribuidas en las cercanías de la posición del río (ver capa de napas freáticas en el Atlas Regional). Estas características orográficas se transforman, al mismo tiempo, en las amenazas que sufre actualmente el suelo en su uso, dos consecuencias debido a la acción pluvial. Una es la anegación ${ }^{28}$ de las zonas bajas por saturamiento del suelo, la otra es la inundación ${ }^{29}$ debido al aumento de los cauces del río Imperial y esteros que componen los territorios. Esto se acrecienta con la acción antrópica (la acción del hombre), sumándose como una amenaza la acción forestal y la exterminación del bosque nativo, pues la forestación potenciaría la erosión hídrica, al lavar la tierra de todo nutriente a través del escurrimiento superficial.

Pudimos constatar en terreno la acción de algunas medidas paliativas y de beneficio a la forestación, como son los surcos que frenan en parte el escurrimiento, aprovechan los nutrientes arrastrados por el agua y que se depositan en estos surcos donde se plantan los árboles. Esta acción se denomina "cota de nivel" y es bonificada por la CONAF y el INDAP como medida paliativa frente la erosión, en su mayoría de laderas, ya que se presenta como un riego natural ${ }^{30}$, lo mismo que la plantación de exóticos.

La acción forestal descompensa la composición química de los suelos, a diferencia de la existencia del bosque nativo, puesto que este es un ecosistema que cumple una función multipropósito dentro de la vida mapuche. $\mathrm{El}$ bosque permite el surgimiento de una diversidad de flora y fauna, que le provee al suelo un crecimiento y una mejor distribución de los nutrientes, manteniendo una homogenei- zación de la composición química del suelo; proporciona la generación de lawen (remedios) dentro del sistema medicinal mapuche; suministra frutos y plantas comestibles estableciendo una dieta diversa, compensada con los animales existentes en el ecosistema; se encuentra la madera para la construcción de viviendas para el clima regional; y facilita la recolección de la leña necesaria para la calefacción.

En los suelos, que van desde los rojos arcillosos hasta la roca metamórfica, se encuentran mayoritariamente las clases IV, VI, VII y VII ${ }^{31}$, siendo la clase IV la más apta para la agricultura; el resto puede ser invertido en la producción forestal, coincidente con el pronóstico del Atlas Regional, aportando que las personas de los territorios, hoy en día, estarían optando por los bosques a las plantaciones forestales.

Podemos agregar que, desde el punto de vista de la localización y conectividad, la ciudad de Carahue aparece como el gran referente. En el caso del territorio de Koliko, se ubica a 5 kilómetros (aproximadamente) al norte de la ciudad. La cercanía a la ciudad explica, en parte, que se haya impedido al territorio poseer su propio cementerio, puesto que antiguamente poseían un eltun (cementerio mapuche) que nunca fue autorizado, teniendo que usar el cementerio de la ciudad hasta ahora. Por otro lado no cuentan con una estructura de salud, viéndose obligados a recurrir a la ciudad para atender sus necesidades médicas. Koliko mantiene solo una escuela básica de carácter municipal. Para trámites organizacionales y algunos temas relacionados con la salud, Temuco sigue manteniendo una gran influencia, tanto en la parte administrativa como en los servicios que posee, que van desde las prestaciones médicas a otros ámbitos relacionados con la economía. La producción comercializable todavía se articula hacia Carahue.

\footnotetext{
$27 \quad$ Ibíd.

28 La anegación se produce por la saturación de agua en el suelo en el proceso de infiltración, por lo general ocurre en las partes más bajas y muchas veces es potenciada por el agua de escurrimiento superficial.

29 La inundación ocurre cuando un caudal aumenta, desbordándose y ocupando superficies.

30 Ibíd. 93.

31 Ibíd.
} 
El territorio de Koliko y su conformación histórica

\section{Historia, asentamiento y familia}

La mayoría de las familias de Koliko manejan la información que su población obedece a unos 150 a 200 años de asentamiento. Los datos históricos los obtuvimos en la segunda reunión de COPAG en el territorio $(28 / 10 / 2004)$. Los comuneros de la comunidad Pedro Curriñir reconocen que vienen del sector de Arauco, de Cañete principalmente, lo mismo que la comunidad de Antonio Chaucono. Mientras que gente de la comunidad Antonio Levío, identifica su sector de origen en Nacimiento y Negrete, para el caso de la comunidad Andrés Maliqueo solo reconocen que poblaron dicho espacio. Lamentablemente no tenemos la versión de la Comunidad Pedro Huilipan. Según el informe redactado por Ernesto Huenchulaf, para la primera etapa de la ejecución del PTD, describe lo siguiente:

"De acuerdo a los antecedentes testimoniales de los miembros del lof, podemos aproximarnos a las formas de asentamiento y característica de movilidad territorial de las familias que actualmente constituyen la población del territorio de Kolüko. Se produjo a través de grupos de familias o xokinche (núcleo familiar) que al parecer provienen de una sola raíz. Una vez que llegaron, cada xokinche se fue estableciendo en un espacio determinado, todos aledaños. "...aquí, en ese tiempo llegó una sola familia, fue un gran grupo de familia, ahora ya no son toda las mismas familias, siempre llevan distintos apellidos, ¿no?, pero antiguamente era una sola, según la familia de nosotros también viene de ese lado" (Julio Cayuqueo, Lonko de Chaukono, septiembre de 2004). Cuando el lonko Julio se refiere a que también provenían del mismo lado se refiere a que un tiempo fueron inmigrantes lafkenche y que tenían su origen anterior por el lado de Negrete. "Pichi allküpan feichi zugu, inchiñ xipaiñ iyiu Negrete püle pikefuigün taiñ pu füchakeche, fei inaltu nopaiñ lafken pigün, fei ta akuigün Tirua mapu püle fey püle rukaigün, fei ka akuig Xofürwe püle, fey püle ta kiñe küyen parece mülepaigün fey adentuülaigün, ka xipaigün ka akuigün ta monkul pigechi mapu, ka semana paigün rukaigün, ka azentulafigün chi mapu, ka xipaigün fei, fey akuigün ta chi Champülli pigechi mapu, pu füchakeche faw anüpaigün". Como todo proceso tiene su propia dinámica, en este caso las familias Lafkenche con los emigrantes que se establecieron en Kolüko, en un comienzo mantuvieron relaciones sociales familiares; tal como lo señala en propio lonko Julio Cayuqueo "muchas veces se visitaban antiguamente o cuando ellos pasaban con kollof (cochayuyo) en esos años ellos eran parientes por eso llegaban acá". En resumen se puede afirmar que en el territorio de Kolüko todas las familias actuales tienen un tronco de ascendencia y procedencia común, Tuwün Küpan, aunque en la actualidad existan diferentes apellidos".

Reforzando lo expresado por el lonko Julio Cayuqueo, la comunidad Antonio Levío agrega las causas de la movilidad de población:

\begin{abstract}
"Nuestras familias antiguas venían arrancando de la guerra desde Arauco, perseguidos por los españoles. Vivían específicamente donde se encuentra Negrete y Nacimiento, venían de esos lugares arrancando de la guerra, buscando tierras donde quedarse" 32 .
\end{abstract}

Recordemos que la Primera Parte es relatar la historia de la comunidad, por lo cual, como actividad, cada una insertaba en ella lo que creía relevante, en el fondo la historia se convierte en un ejercicio de la memoria colectiva del grupo social, un proceso reivindicativo. La mayoría de ellos plantearon el tema del lugar de origen, lo que bajo el concepto mapuche se designa como Tuwün, refiriéndonos a las pautas sociales que se generan en un espacio determinado, y el Küpan, que se refiere a la circulación de ciertos conocimientos, actitudes y características de un grupo familiar. Sin duda, la última frase referida a las visitas y los productos que estos comercializaban era en el fondo la matriz cultural que alguna vez fue parte de ellos y que fundieron en sus personalidades individuales y colectivas.

Comunidad Antonio Levío, 2003, Plan de Desarrollo de Comunidad, Programa Orígenes. Carahue-Chile. 
Analizando la segunda cita de la Comunidad Antonio Levío, y retomando parte del marco teórico, vemos que la movilidad de la población era intensa, pero, al mismo tiempo, poseía objetivos que no se mencionan en el texto. Un tema es huir de la guerra, atribuyéndole un factor de movilidad o desplazamiento de la población, pero otra es aceptar un lugar de asentamiento. Como vemos, traen un tuwün lafkenche, lo mismo que su küpan, lo lógico era que buscaran un espacio frente al mar, puesto que existían vastas zonas desocupadas, los mismos relatos hablan de distintos sectores por donde transitaron. Hay gente que nombra como parte de los asentamientos temporales anteriores a Champulli y otros a Puerto Saavedra en la costa, los Cayuqueo nombran su paso por Malalche (en Cholchol), Boroa y Ragiñtuleufu, con ello podemos concluir que el movimiento no se desarrolló de manera planificada, pero el fondo es que justamente eran una gran familia y que al reencontrarse en Koliko fue uno de los elementos que potencializaron el asentamiento. Fuera de esto, el territorio cumplía con las condiciones ambientales que ellos aspiraban, perfectamente podrían haberse quedado entre Rucacura y el río Moncul, como otras comunidades provenientes de Arauco lo hicieron, como lo relata la investigación de Christian Martínez. Este autor identifica la acción extractiva del mar como causa de asentamiento, y a los cerros vírgenes como una limitante al desarrollo de la agricultura (1995; 50-51). Para nosotros, como la manifestamos anteriormente, vemos al bosque como un ecosistema que articula recursos materiales y espirituales, ya que los winkul (cerros) y mawiza (montañas) poseen sus gen (dueños), los cuales son fortalezas espirituales para el mapuche. El bosque es, además, una unidad productiva que estimula la caza y la recolección, esto se suma a la extracción marina, sea la pesca y la marisquería, la cual genera excedentes y capacidad de intercambio comercial, existiendo una última articulación, la horticultura, todo ello genera un sistema alimenticio y económico, que fortalecen un sistema de creencia particular desarrollando la identidad territorial. Esto es una elección cultural, de ahí que es necesario reflexionar acerca del planteamiento que Henchulaf expone, respecto a lo que refiere a Koliko:

"El fenómeno que se puede inferir en este proceso de reasentamiento es el surgimiento de nuevas identidades o tal vez es un cambio o transformaciones identitarias. De ser lafkenche pasan a desarrollar un sistema de vida relacionado principalmente con la tierra, Wenteche. Siguiendo con la consangueneidad común, don Julio manifiesta, "yo por lo que vi un poco en el Titulo de Merced, ahí estaban los füchakeche Lonko, actualmente permanecen en los Títulos de Merced y también aparecen las personas; con qué familias se casaron, entonces de allá de Chanko el Abuelo, su abuela es descendiente de Koliko, el tío mío también, entonces entre Cayupil y queo ${ }^{33}$, no sé si eso venían sin apellido o venían con algún apodo, cuando llegaron acá y aquí se pusieron nombre, aquí varias familias, aquí se encontraban los Cayuqueo, los Curivil, los Huichaqueo y Rain, eran una sola familia. Yo escuché varias veces los weupin, pero uno hecha una pasadita no más, nunca le da importancia" (Julio Cayuqueo, Lonko de Chaukono) "... lo mismo ocurre en la comunidad Antonio Maliqueo, eso me conversaban también, algunos de ahí, por ejemplo están los Pichingual, Llancaleo, Levio, Currihual; eran todos hermanos y como eran nombres que se pusieron y los winka les puso como apellido, era el apodo" (ídem)

Como apreciamos, la unidad de un mismo küpan y tüwun es lo que hace posible la reconversión territorial. Es el capital humano, utilizando un lenguaje bourdiano, el que permite consensuar un espacio de asentamiento. Pero este proceso no es tan cerrado, involucra la conexión con otros espacios a través de mecanismos sociales, como los matrimonios. Por ejemplo, pudimos construir una pequeña tabla con algunos datos entregados por la comunidad Antonio Chaucono:

33 La terminación queo tiene relación con el kupan, en cuanto a linaje, y tuwun, en relación a la procedencia, con ello se establece el $a z$ mapu, como anteriormente mencionábamos. 
Cuadro de familias del territorio de Koliko

\begin{tabular}{|l|l|l|l|}
\hline $\begin{array}{c}\text { Familias emparentadas } \\
\text { que llegaron }\end{array}$ & \multicolumn{1}{|c|}{ Lugares } & $\begin{array}{l}\text { Familias emparentadas que } \\
\text { se han ido a otros lugares }\end{array}$ & \multicolumn{1}{|c|}{ Lugares } \\
\hline Curiqueo & Taife & Huenchual-Curiqueo & Com. Pedro Huilipan \\
\hline Huenchual & Taife & Cayupil & Com. Pedro Curriñir \\
\hline Toro & Chacay & Maliqueo & Com. Pedro Curriñir \\
\hline Calil & Trapico & Cayuqueo & Calbuko \\
\hline Curriñir & Antonio Levío & Cayuqueo & Llecomahuiza \\
\hline Painecura & Andrés Maliqueo & Curifuta & Champulli \\
\hline Huenchual & $\begin{array}{l}\text { Lolokura y Antonio } \\
\text { Levío }\end{array}$ & & \\
\hline
\end{tabular}

Elaboración propia, para PTD Programa Orígenes.

Según los datos, la mayoría de las personas que circulan son mujeres ${ }^{34}$. Milan Stuchlik reparó en este detalle al aplicarlo a las comunidades de Cholchol cercanas a Coipuco, estableciendo intensidad y distancia en el proceso de circulación de mujeres (1999; 36-38), delimitando una zona vital, que para nuestra conceptualización sería una unidad socioterritorial, como lo puede ser un rewe o un kiñel mapu. El cuadro, sumado a la composición de las familias, como lo señala don Julio Cayuqueo, nos indica que la mayoría de las mujeres circularon al interior de las 5 comunidades, manteniendo relaciones sociales hacia la costa, hacia el sur y, en menor medida, hacia la depresión intermedia. Es más, algunos apellidos, como los Huenchual, se han distribuidos al interior de los lof de Koliko. Siguiendo con la idea de las familias y la importancia en la construcción territorial, podemos ver lo que plantea la comunidad Antonio Levío:

"Nuestro primer lonko fue Antonio Levío, era un buen weupife y era palife de primera, el paliwe de la comunidad esta ubicado donde vivía él...".

"El kupalme de esta comunidad es Llancaleo y Llancañir, después de los Llancañir cuando la radicación, los winka lo inscribieron como MENDOZA".

Como se demuestra, el küpan marca el prestigio y la característica social de los lofche, primero que nada dice cuál es su conocimiento específico y el rol que cumple, por ejemplo Antonio Levío es weupife y lonko, por lo cual aparece representado como un hombre respetable y con una legitimación para ejercer cargos y liderazgos, pues el weupife es el encargado del Kuifi (pasado) en todas sus dimensiones, un hombre con conocimiento del sistema filosófico, la historia de su pueblo, el kimun (sabiduría) y el rakizuam (pensamiento) y capaz de utilizarlo como longko, con lo que el prestigio crece para su lof. Al identificar las familias el Kupalme, identifica al grupo encargado de transmitirlo a través de generación en generación al interior de la familia como en el lof. Como podemos apreciar, estos conocimientos tienen una vertiente familiar y una colectiva, por ejemplo en el caso de la comunidad Pedro Curriñir:

"Los Panchillos viven pocos porque la mayoría de la descendencia fueron mujeres. Al contrario los Cayupil aumentan, ya que tiene más descendiente varones. Esto se ve en la ocupación que tienen hoy en cuanto a la cantidad de hectáreas que ocupan las familias. Otros de los fenómenos es la de la familia Hidalgo, este era un winka que llegó a trabajar y se unió con los $\mathrm{Cu}$ rriñir, hace unos 60 años. De ahí que esta familia se haya multiplicado. Obviamente no aparece en el Título de Merced".

Por ejemplo, en los apuntes tomados de la comunidad Pedro Curriñir, en el segundo taller de COPAG, hay un fenómeno que se produce en el kimun y la relación con el kupalme, por ejemplo si disminuyen los Panchillo, por los motivos que ellos los señalan, su kimun se va reduciendo, ya que se impone los 
conocimientos y prácticas del linaje paterno. Esto tiene un efecto político, ya que queda en minoría. Pero puede darse que el linaje mayoritario no posee los conocimientos para ejercer el poder, aunque pueden ser muy buenos en otras áreas, en este caso puede lograr mantener el poder un linaje menor. Para el caso de los Hidalgo, la gente ve que es una familia que ha aumentado rápidamente, con una visión distinta y que ha ido ejerciendo una cierta influencia más occidental.

Por último, también existieron las divisiones familiares y ello provocó el nuevo surgimiento de apellidos que actualmente se consignan en el territorio, como lo señalan en la comunidad Andrés Maliqueo: "Todos eran de una u otra forma familia, pero como de repente se enojaban entre ellos y peleaban se iban poniendo apellidos distintos, para no ser familias entre sí".

En la comunidad Pedro Curriñi ocurre que los Nahuedlñir pasaron a ser Nahuel. Por lo informado, serían más los casos.

\section{Medio ambiente}

Volviendo a la ocupación del espacio, la comunidad Andrés Maliqueo nos señala lo siguiente:

"...en ese tiempo eran montañas vírgenes, donde había mucho coligüe, maque, roble, quedaban los pellines. Nadie se atrevía a cruzar el bosque, ni siquiera el español o winka. Entonces llegaron los mapuche a habitar el territorio, primero que nada cuidar los animales y a trabajar, como hacer distintos tipos de artesanía en madera pellin, batea, canoa, poste para construir sus casas (ruka) Tuvieron que destroncar, sacar coligüe y rozar para tener más espacio para cuidar sus animales y también sembrar para sobrevivir de a poco".

Sin duda, los bosques proveían cercos naturales para el ganado, proveían de materia prima para elaborar artefactos de uso doméstico, presentaban una defensa para incursiones winka o mapuche. Es por ello que afirmamos que los ecosistemas responden a múltiples propósitos en la vida mapuche, aun los wampo (canoas funerarias mapuche) estaban aseguradas para los ritos fúnebres. Incluso los mapuche hacen el análisis comparativo de forma inmediata, como ocurre con la comunidad Andrés Maliqueo:

"Ahora hay más hectáreas limpias para trabajar, pero los terrenos ya están erosionados (lavados), por el agua lluvia o muy trabajado. Hay un $75 \%$ con pendientes severas y un $25 \%$ parejo, pero de esos $75 \%$ tienen la mitad ya plantaciones de pino y eucaliptos, por eso que las vertientes que antes habían ya no están. Por eso tenemos que tener mucho cuidado en poder mantener en buen estado nuestro poco terreno que nos han dejado nuestros antepasados. Porque esto fue ganado con la lucha y con orgullo tenemos que cuidarlo"35.

La gráfica con que las personas mapuche nos muestran su actual desprotección frente a la pérdida de los ecosistemas mapuche, obliga hoy a resguardarlos. Mencionan que la retirada de la vegetación nativa comienza a afectar a las aguas. El problema no se zanja aquí, el agua como recurso es utilizado para la agricultura, ganadería y el uso doméstico, por lo que cualquier intento de desarrollo intrapredial pasa por asegurar este recurso.

\section{Aspectos culturales}

Pero como señalábamos al comienzo de esta investigación, las relaciones interétnica son un elemento relevante al analizar los cambios sociales y la alteración de aspectos importantes en la cultura. La comunidad Antonio Levío nos muestra lo siguiente:

"Los Gijatunes antes era con un respeto máximo, cuando los lonko hablaban de gijatun nadie ni por más pobre que fuera se quedaba en la casa, todos asistían con la voluntad de participar, los lonko eran muy respetados, los capitanes hacían respetar lo que la machi y el lonko decían, las ceremonias en nuestro lof las ha dirigido una machi. Un lonko que se destacó en el lof fue Segundo Llancaleo que era de esta comunidad, los lonko tenían como grado,

35 Notas de Campo. Reunión COPAG. Agosto 2003. 
este lonko sabía kuipicar, sabía de kupalme de las familias del lof, pues todas las familias venían de un mismo lugar y les gustaron estas tierras cuando arrancaron de la guerra y aquí se quedaron".

En la primera parte de esta cita, las personas plantean el modelo social anterior a la invasión militar, el hecho de la participación en los espacios socioculturales, como son el Gijatun, la disposición y el respeto, el rol $y$ el mantenimiento de una ceremonia. Cabe señalar que en la actualidad existen varios gijatunes en el territorio de Koliko, pero lo que prima son las características de gijatun, que es dado por el küpan y el tüwun; como ellos lo explican, el elemento fundamental que sostiene al territorio en el origen familiar.

"Antiguamente los lonko solucionaban los conflictos del lof, el palin era diferente, los jugadores se echaban grasa de caballo en el pelo para que no los agarraran o se cortaban el pelo bien corto, existía una preparación previa antes de jugar, no se dormía con la esposa, se tomaba agua de los palos huecos que se juntaba de la lluvia. ... recordamos en la actualidad existe un machi en nuestro lof, que es de otra comunidad, el gujatun ha cambiado bastante, se ha awincado, la rogativa de la machi no cambia, el eluwun (funeral tradicional) se práctica con la gente más anciana del lof, en nuestra comunidad ya no, el lonko que tiene nuestra comunidad en la actualidad es evangélico y renunciará a su cargo por esta razón".

Con esta segunda parte del relato, comenzamos a ver los efectos de la relación con el otro. El palin, como sistema normativo y de resolución de conflictos, no puede ser mirado como parte del ceremonial mapuche folclorizado, sin mencionar su función social que cumple. Con ello las personas nos muestran la existencia de una institucionalidad que aplica una resolución de conflictos en base al consenso y la participación, nos muestra los procedimientos que se forjaron en miles de años de libertad como sociedad, contraponiéndose al uso deportivo que tiene actualmente. Pero las ceremonias se han ido extinguiendo, la falta de recursos y la desactivación de los aspectos centrales de la cultura han llevado a lo que se describe en la segunda parte, a que el eluwun solo se le realice a las personas más antiguas y el dejar los cargos por pertenecer a otra religión. Estos aspectos quieren ser revertidos por las personas del territorio, es por ello que son denunciados, puesto que se está en una situación de cambiar el presente, ellos han visto cómo la religión y la política partidista superpone otros intereses, abandonando los intereses del colectivo de origen; ante ello más adelante veremos las propuestas que las propias personas y los dirigentes del territorio ven.

\section{Relaciones interétnicas en el siglo XX}

Para cerrar este ciclo recurriré a una última cita que refleja las responsabilidades que todas las personas tienen frente al tema mapuche y que nos lo entrega la comunidad Antonio Levío:

"Nuestra vida acá fue buena si pensamos en lo que sufrieron nuestros antepasados en Arauco, pero esto cambió para nosotros cuando éramos niños y tuvimos que asistir al colegio, por nuestra cercanía con la ciudad de Carahue asistíamos a un colegio allá, ahí éramos mal mirados, nos trataban de indios y a las mujeres de chinas $y$ otros insultos fuertes, esta época fue triste, como éramos pobres íbamos descalzos al colegio, pantalón a media canilla, camisa sin cuello, más mal nos miraban. Llevábamos de rokin un pedazo de pan o un poco de harina y nos instalábamos en la llave a comer agua con harina, nos molestaban por nuestra forma de hablar, no hablábamos bien el castellano. Esto de alguna manera nos fue alejando de nuestra lengua,..., nuestros padres querían que aprendiéramos el castellano, para que no se rieran de nosotros. En los años 50 ya no hablábamos tanto mapuzungun, pero igual hablábamos mal, hasta el profesor se reía...".

Sin duda esta cita grafica lo que siente un país colonizado, con una ideología del otro como inferior, sin una defensa de su dignidad. Mucha gente rehúsa la historia y el trabajo al interior de la cultura, al igual que la intención de la Educación Intercultural Bilingüe, han visto la historia del siglo XX como una historia de penuria, de humillaciones, pobreza, y agresión. Una historia llena de privaciones, por lo cual no reivindicada en los aspectos 
generales, solo salvo en aquello donde se pueda generar justicia frente al usurpador o en aquellos puntos que nos muestran radicalmente opuesto al winka, pero no en función del otro, sino en la posibilidad de levantar un nuevo referente capaz de sacarnos de la actual situación colonial. Como la gente relata, la educación no sirvió para que la gente hable mejor el castellano, en muchos casos fue un centro de tortura, de vejación de la dignidad, cuántos docentes se habrán reído de sus alumnos mapuche por no saber hablar, pareciera ser que la voluntad política por integrar al mapuche como igual nunca bajó de los discursos, fueron las diferenciaciones las que en cierta medida nos mantienen unidos, al decirnos los winkas con sus actitudes que no somos iguales a ellos.

\section{La continuidad de la historia entre los cam- bios}

Cuando se inició el PTD en el territorio de Koliko, una de las primeras actividades eran las reuniones informativas Estas buscaban incentivar a la gente a participar en el Plan. Estas reuniones cumplían, en la prácti$\mathrm{ca}$, un doble propósito, informar a la gente y recoger las inquietudes y los espacios para levantar una propuesta de trabajo cada vez más concreta. Para este trabajo se desarrolló una metodología; utilizar grabaciones y transcribir los planteamientos de las personas.

De esta manera comienzan a surgir los conceptos y categorías utilizadas por las personas, como el kümelkaleal (estar bien) (Ancalaf; 2004;3) y su contrario, "no estar bien". Ocurre que muchas veces las personas no pueden definir directamente los conceptos y para eso se ayudan del contrario, identificando, por añadidura, los elementos del kümelkaleal. Por ejemplo, de aquí obtuvimos un listado de variables que indican estar o no estar bien:

1. La falta de comunicación. Para ello la pérdida del mapuzungun es un factor de "no estar bien" porque impide la comunicación entre el más joven y el más viejo. Como señalamos en nuestro marco teórico, hay palabras que no tienen traducción y veíamos en las historias de los territorios, que las personas mayores no saben hablar bien castellano, con lo que no pueden expresar totalmente su pensamiento. Fuera de ello, las personas están de acuerdo que se hable bien el mapuzungun o el castellano a que se hablen los dos a medias.

2. Otro tema es el desconocimiento de la historia, sobre todo en los jóvenes. Esto genera que se pierdan los lazos filiales, que las personas se distancien entre sí, porque no comparten ningún proyecto común. Lo que lleva a pensar en la urgencia de la articulación de una educación mapuche, pues se evidencia que los problemas se están dando en tres niveles, familiar, intra-lof e interlof. Al no hablar mapuzungun, los jóvenes desconocen los discursos realizados en las ceremonias mapuche. Sin duda, aparece el concepto del kuifi (pasado) para trabajar el presente, pues este concepto mapuche involucra el pasado en dos dimensiones, la cultural como sociedad y la relacionada con la historia vivida, ambos como elementos de reclutamiento social, de afianzamiento de la identidad, a tal grado que no se cuestione.

3. El debilitamiento de las relaciones sociopolíticas mapuche y la labor organizacional. Cada vez más se han ido debilitando las estructuras inter e intralof, afectando el sistema organizativo en general, pues da pie a que organizaciones funcionales, de carácter coyunturalistas y de objetivos del corto plazo, asuman esta función, perdiendo la perspectiva futura de desarrollo y caigan en una dependencia con los servicios públicos, siendo fácilmente captados como clientela política. Otro peligro relacionado con ello es que divide a la gente y desgasta a las personas que ejercen las labores dirigenciales en trámites y disputas al interior de las comunidades.

4. La pérdida de prácticas culturales y formas sociales de reclutamiento. Las transformaciones sociales se han caracterizado por pérdidas de pautas culturales de comportamiento, las cuales refuerzan los lazos filiales que mueven a la sociedad mapuche, entre ellos está el pentukun, las visitas entre los familiares y amigos, la interacción del trabajo comunitario que refuerzan la noción de solidaridad. 
5. Los conflictos por tierras, intralof y comunidad, y los conflictos con particulares, generan una serie de disputas al interior de las familias como con otras familias del territorio.

Sin embargo, existen potencialidades que podemos trabajar desde la perspectiva mapuche, por lo menos se evidencian dos con toda claridad:

1. Las prácticas culturales existentes en algunos lof: el gijatun, el palin y el eluwun. Esto nos abre un espacio a la reflexión acerca de sus significados y las formas de proceder en dichas ceremonias.

2. La existencia de personas que manejan el kimun de los territorios, esto permitiría construir las historia del asentamiento y de construcción social del territorio.
Las personas del territorio manifiestan el "no estar bien". Plantean los elementos a trabajar y qué sería lo óptimo. Con esto podemos establecer una imagen para conceptualizar el "estar bien" que involucraría a) una unión intra e intergeneracional, b) una reestructuración social y política, con valores como la solidaridad, respeto y fortalecimiento de los lazos filiales, y c) asumir la identidad territorial y su historia, por lo cual va quedando claro el camino que la gente quiere transitar. Lo que brinda esperanza es que un gran número de jóvenes en los territorios está trabajando de manera activa en este proyecto social en construcción. Es por ello que queremos finalizar con tres productos que la gente elaboró en los territorios, entre jóvenes y mayores.

Cuadro de los espacios sociales en los territorios

Espacios Sociales de Koliko ${ }^{36}$

\begin{tabular}{|c|l|l|l|l|l|}
\hline$N^{\circ}$ & \multicolumn{1}{|c|}{ Comunidad } & Tierras usurpadas & \multicolumn{1}{|c|}{$\begin{array}{c}\text { Espacio dotado de un } \\
\text { gen }\end{array}$} & \multicolumn{1}{|c|}{$\begin{array}{c}\text { Espacio } \\
\text { sociocultural }\end{array}$} & Espacios sociales \\
\hline 1 & Andrés Maliqueo & & $\begin{array}{l}2 \text { Xayen } \\
3 \text { Menoko }\end{array}$ & $\begin{array}{l}\text { Eltun } \\
\text { Paliwe } \\
\text { Gijatuwe }\end{array}$ & $\begin{array}{l}\text { Sede social } \\
\text { Iglesia evangélica }\end{array}$ \\
\hline 2 & Antonio Chaucono & 30 ha & $\begin{array}{l}2 \text { Menoko } \\
2 \text { Mawiza }\end{array}$ & $\begin{array}{l}\text { Paliwe } \\
\text { Eltun }\end{array}$ & $\begin{array}{l}\text { Sede social } \\
\text { Capilla católica }\end{array}$ \\
\hline 3 & Antonio Levío & $\begin{array}{l}\text { Xegxeg } \\
\text { Mawiza } \\
5 \text { Menoko } \\
\text { Wüfko }\end{array}$ & Paliwe & \\
\hline 5 & Pedro Huilipan & Tierra usurpada & $\begin{array}{l}3 \text { Mawiza } \\
3 \text { Menoko } \\
3 \text { Wüfko }\end{array}$ & $\begin{array}{l}\text { Paliwe } \\
\text { Eltun }\end{array}$ & Sede social \\
\hline
\end{tabular}

Este cuadro nos muestra que hay un conocimiento que está en los territorios esperando ser activado. Este cuadro que puede parecer sencillo, involucra un reconocimiento de los espacios tanto mapuche como introducidos, pero al mismo tiempo, esto demuestra un conocimiento acerca de los significados mapuche. Este cuadro permitió la interacción entre los jóvenes y mayores quienes no solo identificaron los espacios, también los explicaron. Reforzando y aclarando las nociones que tenían. 


\section{Propuestas de desarrollo mapuche}

Para finalizar y de alguna manera reforzar su pensamiento, las personas del territorio plantearon elementos constitutivos o fundacionales para su accionar dirigencial y de pensamiento mapuche, para ello establecieron los ejes que desarrollaría el PTD al interior de los territorios.

el desarrollo:

Orientación de los principios-ejes para

a) Fortalecimiento o fomento (chumuechi). En todos los perfiles de proyectos, los programas están relacionados a este tema de fortalecimiento.

¿A qué se refería la gente cuando se hablaba de fortalecimiento?

- Se refería al modelo de vida o el sistema de vida de los mapuche

- ¿Qué implica el modelo de vida mapuche?

En concepto mapuche puede ser el "küme felen", este se refiere a un bienestar que involucra al ser humano y todo lo que los rodea. Este modelo existe en el pensamiento de las personas del territorio, pero no se plasma en la práctica. Referido al mapu se dijo Zapitun mapu, lo que equivale a la preocupación que debe existir por mantener el orden en los espacios, y cuidarlo: "wüño zapitugeael mapu". El kunugey mapu müley ñi ekugeal se refiere al concepto religioso espiritual.

b) El che, modelo de persona que se aspira para el küme felen, bienestar de las personas, lo que implica desarrollar ciertos valores y actitudes referidos a la normativa del comportamiento humano y con el medio ambiente natural que le rodea, con el cual convive. Esto se conjuga en los conceptos de Kümeche, persona que aspira al bienestar material y social, persona que procede de manera solidaria con el otro. Norche, persona recta, justa, honrada y sobre todo respetuosa. Newenche, consecuente con las ideas propias, con una posición política basada en los ideales mapuche. Kimche, con conocimientos y que lo practica adecuadamente.

c) El planteamiento político se puede entender como: kizu günewün y kizu rakizuam, que es la disposición a la autoadministración que se debe ejercer en el territorio bajo un pensamiento político propio del territorio.

d) Kuzugüneluwün: este concepto tiene que ver con las características psicológicas que son propias de las personas que habitan un territorio. Lo psicológico tiene que ver con un proceso de asentamiento que se va generando durante la historia familiar, como tuwün küpan, que involucra los distintos seres espirituales del medio natural con las cuales se ha relacionado históricamente.

Procesos de territorialidad y autogobernabilidad mapuche en Koliko

Como podemos apreciar, no existe un modo ni menos aún una metodología para conocerlo de manera objetiva. Esto queda en evidencia cuando queremos explicar las relaciones interétnicas a partir del uso del territorio y vemos que se mantienen dos sociedades distintas, aunque para el caso mapuche una en subordinación a otra. Los conflictos territoriales se han acrecentado por la falta de voluntad y de enfoques que permitan entender que la pobreza, la marginalidad del pueblo mapuche y su discurso reivindicativo parten desde la necesidad de mantener un colectivo, pero relacionado a otras sociedades. La ciencia no ha sabido responder a las necesidades y realidad social de los otros, simplemente porque se han quedado en su condición de objetos de estudios; su interés ha estado en presentar una explicación coherente o racional a la forma de pensamiento occidental. La posibilidad de conocer la realidad mapuche pasa por establecer nuevas instancias políticas para formalizar consensos respecto a la investigación y posibilidades de desarrollo para dos sociedades en un mismo territorio.

El kimun mapuche aparece como una alternativa para generar nuevos tipos de conocimientos, acercamientos y diálogos; permite reconocer y diferenciar al otro; pero al mismo tiempo, establece la plataforma para establecer los acuerdos, los elementos mínimos para que el pueblo mapuche se pueda desarrollar. Conceptos como territorialidad o control territorial mapuche se fundamentan en el $\mathbf{k i}$ - 
mun, ya que es la construcción de miles de generaciones mapuche, con una estructura abierta que le permite enfrentar los actuales desafíos de la globalización, incorporando y manteniendo sus elementos.

La labor del intelectual, tanto del que investiga como el que enseña, es el establecer un sistema más abierto en término de perspectivas de conocimiento, pero al mismo tiempo reconocer que su opinión no solo es intelectual, también es política, y por ello debe explicitar el contexto bajo el cual observa al otro, describir cómo se interrelaciona con su supuesto objeto de estudio, plantear qué tipo de realidad está generando y cuáles serían las consecuencias de esto. La dinámica del poder no es ajena a la ciencia y la enseñanza, se vive día a día, es cotidiana, es por ello que hay entender cómo se producen elementos que juegan en la construcción social de los territorios y de admitir la adscripción al espacio que uno desearía crear o desarrollar, en un marco de flexibilidad y tolerancia, que nos lleva a modificar las actuales redes de poder.

Para los mapuche, los desafíos de la territorialidad no se terminan en la comunidad, sino que empiezan ahí, en la ruralidad mapuche, y debe viajar, posesionarse de lo urbano. El mapuche actual, mayoritariamente urbano, debe reclutarse en las comunidades, empaparse de su lofche, para apropiarse de la ciudad, no quedarse sumergido en el anonimato, expresar su territorialidad a partir de modificar el espacio urbano, convertirse en colectivo, esto quiere decir, reforzar las redes al interior de la ciudad, como son los lofche. Es por ello que en su momento necesitará construir institucionalidad propia, instituciones que le permitan desarrollarse como colectivo, sean estos centros de diversión, centros médicos, espacios rituales, etc. Elementos que lo agrupen, pero que no discriminen al otro, al contrario, integrar al otro a nuestra cultura. Para ello se necesitan nuevos pactos e investigaciones. Estos son los desafíos que de algún modo nos van a permitir desarrollarnos como sociedades distintas, pero sin perjudicar al otro. Solo la madurez política de los pueblos permitirá la justicia social, un orden social humano y la convivencia pluriétnica.

La globalización, como fenómeno horizontal a todas las sociedades, ha generado transformaciones tanto en las sociedades que poseen Estados Nacionales como en la Naciones Originarias o Indígenas. Dos de los temas más sensibles para el Estado son actualmente la gobernabilidad y el reordenamiento territorial. En el caso de las naciones originarias, unas de las potencialidades que ha abierto la globalización es el intercambio de experiencias y aprendizaje en la lucha por la autogobernabilidad. En este marco las naciones originarias han avanzado en el proceso de ejercer su libre-determinación, siendo la $\mathrm{Na}$ ción Mapuche (Wallmapuche) una de ellas.

Para el caso mapuche, esta situación ha abierto la posibilidad de entrar a un proceso que era demandado por distintas organizaciones a través de la historia, aunque con matices. Es por ello que en la actualidad los procesos de reconstrucción territorial, como una forma de alcanzar grados de autogobernabilidad, han tenido un rápido crecimiento en las comunidades mapuche. Estos procesos están relacionados con elementos culturales y políticos que se han ido conjugando. Fuera de ello han tenido múltiples puntos de partida, encontrándonos en la actualidad con el fenómeno de la inducción del proceso, tanto por el propio movimiento mapuche ${ }^{37}$ como por parte del Estado nacional chileno. Aclarando que esta iniciativa política es más gubernamental que estatal, y que se ha visto plasmado en el desarrollo del Programa Orígenes, financiado por el BID, y con un apoyo político de un sector minoritario de la Concertación de Partidos por la Democracia. Esto también se ha visto reflejado en la creación de instancias, como la Comisión de Verdad Histórica y Nuevo Trato Indígena ${ }^{38}$.

$37 \quad$ Para ello se puede ver en cierto sector autonomista la autoidentificación por los sectores territoriales que antiguamente existía al interior del pueblo mapuche como Nagche, Wenteche, Williche, etc. Con lo que actualmente hay una doble identidad, uno como mapuche para identificarse ante la población chilena, y otra para identificarse al interior del pueblo mapuche, en términos de localidades.

38 Actualmente, una gran mayoría de los dirigentes funcionales de las comunidades desconocen del alcance de esta comisión y de otras instancias académicas para el tema de una verdad histórica. El impacto en las escuelas de iniciativas de gobierno es casi nulo. En el territorio de Koliko las comunidades no mantienen un vínculo estrecho con las escuelas, por lo que se hace difícil la implementación de programas de Educación Intercultural Bilingüe (EIB). 
Estos procesos carecen de una sistematización rigurosa en cuanto a su trabajo. Esto se debe a que el movimiento mapuche no ha establecido una estrategia clara frente al asunto y, por otra parte, el Estado ha tenido que derivar el trabajo en terreno a consultoras que no necesariamente comparten el proyecto político del gobierno y/o de las comunidades. Esta primera parte del proceso actual se ha caracterizado por una descolonización ideológica, abundando los cursos de Cosmovisión Indígena e Historia, pero al mismo tiempo las comunidades mapuche (rurales) han formulado la discusión sobre la reconstrucción del territorio ancestral. Cabe mencionar que el territorio mapuche fue incorporado solo hace 125 años. Los procesos inducidos han establecido la importancia de la planificación territorial y la necesidad de profesionalizar la gestión dirigencial.

En este proceso el movimiento mapuche no ha podido ser del todo efectivo, pues la ausencia de cuadros técnicos y una estructura más centralizada o de coordinación le ha impedido responder ante las demandas de las comunidades, ya que hay que mencionar que el actual movimiento está centrado en la ruralidad, por lo que queda un vasto trabajo hacia la población urbana del pueblo mapuche ${ }^{39}$. Se ve a futuro, por los ensayos de estrategias, alcanzar cuotas de poder local a través de las lecciones ${ }^{40}$. A esto se suma un discurso de base que va tomando forma y que apunta poco a poco a un proyecto autonómico. Sin duda la aspiración de autogobernarse y ejercer la libre-determinación como pueblo, desde el nivel local y más adelante regional, es un proceso que no va a poder ser frenado, a los más intervenido en su conducción.

En la actualidad existe una precaria sistematización de dos tipos de procesos, el proceso cultural de reconstrucción territorial y el proceso inducido. Ambas dejan claras diferencias en sus procesos y en sus objetivos. La reconstrucción cultural se inicia en la recuperación de los espacios públicos, sociales y de carácter ceremonial, liderado y regulado por pautas culturales propias y con una alta responsabilidad en las autoridades tradicionales ${ }^{41}$. A diferencia del primer proceso, el proceso inducido parte, generalmente, de dirigentes funcionales, centrados en aspectos como la obtención de beneficios, articulados con los organismos públicos y participación interna de las comunidades. Muchos de ellos también buscan una mayor participación y rol de las autoridades tradicionales. Los formatos utilizados por los procesos inducidos no corresponden totalmente a la lógica cultural propia, como por ejemplo las capacita-

39 Uno de los problemas que tienen en la actualidad los mapuche es el de los puntajes en los índices de pobreza, debido a que los instrumentos aplicados, como Encuestas CASEN y CAS, solo se apoyan en los bienes que existen al interior de un hogar y no analizan la forma de adquisición y calidad de los bienes. Gran parte de estos bienes son subvencionados por los mapuches urbanos o inmigrantes a las ciudades. Actualmente no existe un estudio serio de este tipo de articulaciones económicas en el Pueblo Mapuche.

40 El territorio de Koyawe, perteneciente a la comuna de Carahue, intentó llevar a la reelección al Machi Víctor Caniullan. En general, este proceso eleccionario, a través de la propaganda, permitió difundir y reflexionar en muchas comunidades sobre el proceso de reconstrucción territorial, sobre todo en las comunas donde iban candidatos mapuche. Hay que mencionar que esta idea está solo en una minoría de la población y los dirigentes mapuche, pese a que se ha ido extendiendo. De los tres casos estudiados, las personas que participan en este tipo de reuniones y reflexiones equivalen al 10\% de su población, pero lo que llama la atención es la incorporación del segmento joven en complementariedad a los más antiguos, esto vale tanto para las reuniones como para las ceremonias religiosas, pese a la disminución del uso de la lengua mapuche.

41 En Koliko hay ideas parecidas, como la conformación de un organismo colegiado entre dirigentes funcionales y autoridades tradicionales, lo ven necesario para la administración del territorio y sus recursos.

42 En el territorio de Koliko se llevaron a cabo 3 reuniones informativas, en el plazo de dos a tres meses y 3 reuniones para trabajar con un grupo representativo de la comunidad para establecer las problemáticas del territorio, responsabilidades y propuestas. Finalmente se organizaron 5 módulos para microplanificar el territorio y su reconstrucción. El primer módulo tocó puntos de la cosmovisión como territorialidad, educación y salud; los siguientes módulos estuvieron orientados al tema de la gestión y relaciones con organismos gubernamentales y experiencias autogestionadas exitosas. En general, el trabajo se orientó más a las relaciones con el Estado que a su interior, es por ello que se reforzó con talleres de profundización, los cuales se dividían en áreas temáticas como salud, educación, producción y organización, en los cuales se analizaba el territorio. Hay que destacar la participación de autoridades tradicionales y jóvenes. Sin duda, la voluntad política existente en las personas permiten un trabajo de estas características, pues para ello involucraba sacarlos de sus dinámicas y forzarlos a trabajos que en muchos casos les eran desconocidos. Se han comenzado a romper las cadenas del asistencialismo y de dependencia para pasar a un nuevo tipo de relación Intra e Interétnico. Por último, cabe mencionar que por lo nuevo del proceso los resultados los veremos en unos años más, sin embargo, queda mucho para la conducción de estos proceso. 
ciones ${ }^{42}$. Estos procesos han llevado a pensar en forma más consciente una planificación de reconstrucción y administración territorial de manera más participativa, lo que también se ha traducido en la creación de nuevas estrategias políticas para cambiar las relaciones interétnicas con el Estado Nacional chileno.

Para el caso de los procesos culturales de reconstrucción territorial su avance hacia la perspectiva política de relación con el Estado ha sido más lento, aunque de todas formas han visto la necesidad de ser intervenidos para introducir información y conocimiento para llegar a revertir la actual situación de colonialismo, y que se transforma en una dependencia de las estructuras del Estado Nacional chileno.

Ninguno de estos dos procesos son excluyentes y ambos apuntan a reconstruirse desde sus bases para extenderse y lograr la unión como Nación. Es un proyecto político en proceso de construcción, ante lo cual el movimiento mapuche está tratando de responder en sus requerimientos.

Es por ello que se hace necesario sistematizar y analizar las propuestas de reconstrucción territorial, para ir viendo a qué modelo de gobernabilidad hoy estamos aspirando como mapuche y compararla con los procesos que han vividos otros pueblos.

Volviendo a nuestros objetivos de describir, analizar y reflexionar acerca de los elementos y los aspectos que involucra un proceso de reconstrucción territorial, nos señala que existe un modelo aferrado al territorio, que solo es comprensible en la medida en que se participa de él. Por otro lado, en un proceso inducido, como ocurre en Koliko, se clarifican los pasos a seguir en este proceso, en una inserción en la arena política actual, con todos los elementos antes mencionados. Este trabajo ha sido un pequeño esfuerzo para entender las dinámicas de reconstrucción territorial, dejándonos más preguntas que respuestas, dejando más inquietudes que certezas; a lo más, nos ha indicado algunos posibles caminos por los cuales transitar, pero en el que se ve claramente que no se puede ir solo, se necesita de muchos más que exploren y acepten los desafíos que la reconstrucción territorial nos impone y nos conduzcan hacia un proceso de liberación nacional.

Archivos

Archivo Regional de la Araucanía. Fondo Intendencia de Cautín

\section{Bibliografía}

ANCALAF, G.; Huenchulaf, E. \& Cárdenas, P., 2004, Nociones de Tiempo y Espacio en la Cultura Mapuche. Guía didáctica para el profesor. Nivel Básico I; Centro de Desarrollo sociocultural Mapuche, Corporación Nacional de Desarrollo Indígena. Temuco-Chile.

AUKIÑ WALLMAPU, N., 1997, El Pueblo Mapuche y sus Derechos Fundamentales; AWG; Temuco-Chile.

AYLWIN, J. (comp.), 2001, Políticas Públicas y Pueblo Mapuche; Instituto Estudios Indígenas de la Universidad de La Frontera, Ediciones Escaparate, Temuco.

BARTH, F. (comp.) 1976, Los grupos étnicos y sus fronteras. La organización social de las diferencias culturales. Fondo de Cultura Económica. México.

BENGOA, J., 1992, "Las Tierras Indígenas en la legislación chilena", en Comisión Chilena de Derechos Humanos; Pueblo, Tierra, DesarroIlo; Conceptos Fundamentales para una nueva ley indígena.

BOLETÍN ETNOLÓGICO y Cultura Mapuche de la Sociedad Pelondungun; publicación $N^{\circ} 15$, julio de 1991.

CANIUQUEO, S., 2005, Wiñon Mapuche Kisügunehual. De la reconstrucción territorial a la soberanía mapuche, Tesis para optar al grado de Licenciado en Educación, Universidad de La Frontera, Temuco.

COMISIÓN CHILENA de Derechos Humanos, 1992, Pueblo, Tierra, Desarrollo; Conceptos Fundamentales para una nueva ley indígena. Comisión Chilena de Derechos Humanos. Santiago Chile.

COMUNIDAD ANTONIO Levío, 2003, Plan de Desarrollo de Comunidad, Programa Orígenes. Carahue-Chile. 
FIGUEROA, N. (responsable de la edición), 2005, Aprendizaje para la autogestión territorial Mapuche; Experiencias de cinco organizaciones territoriales indígenas. Inédito.

GUTIÉRREZ, M., 1998, "La territorialidad en el proceso de ocupación de La Araucanía: un enfoque Geográfico- Histórico", en Rev. Pentukun $\mathrm{N}^{\circ}$ 9; Instituto Estudios Indígenas de la Universidad de La Frontera; Temuco.

IGM, 1985, Atlas de la IX Región de La Araucanía; Instituto Geográfico Militar; Chile.

MALLON, F., 2004, La sangre y el copihue. La comunidad mapuche de Nicolás Ailío y el Estado chileno 1906-2001, LOM Ediciones, Chile.

MARIMAN, P. (comp), 2002, Parlamento y Territorio Mapuche; Instituto Estudios Indígenas de la Universidad de La Frontera, Ediciones Escaparate, Temuco.

MARTíNEZ, CH., 1995, “¿Identidades étnicas en el mundo mapuche contemporáneo? Algunas implicancias teórico prácticas”, en Rev. Pentukun $\mathrm{N}^{\circ} 2$; Instituto de Estudios Indígenas de la Universidad de La Frontera. Temuco.

COMUNIDADES y Territorios Lafkenche, los mapuche de Rucacura al Moncul, Instituto de Estudios Indígenas de la Universidad de La Frontera, Temuco.

MCFALL, S. (comp.), 2001, Territorio Mapuche y Expansión Forestal; Instituto Estudios Indígenas de la Universidad de La Frontera, Ediciones Escaparate, Temuco.

MOLINA, R., 1995, "Reconstrucción de los Etno-territorios", en: Tierra, Territorio y Desarrollo Indígena, Institutos de Estudios Indígenas UFRO, Temuco-Chile.

MOLINA, R. \& Correa, M., 1996, Territorio y Comunidades del Alto Biobío; CONADI; Chile.

MONTUPIL, F., 1981, Inche Tati. El Pueblo Mapuche: Tradición Indómita en Chile; CIERA, Managua-Nicaragua.

MORALES, R. (comp.), 2001, Municipios: Participación (o exclusión) mapuche, Instituto Estudios Indígenas de la Universidad de La Frontera, Ediciones Escaparate, Temuco.
MORALES, R. (comp), 2002, Territorialidad Mapuche en el siglo XX; Instituto Estudios Indígenas de la Universidad de La Frontera; Ediciones Escaparate; Temuco. 